\title{
Evolutionary engineering of a wine yeast strain revealed a key role of inositol and mannoprotein metabolism during low- temperature fermentation
}

\author{
María López-Malo', Estéfani García-Rios, Bruno Melgar ${ }^{1}$, Monica R Sanchez², Maitreya J Dunham² \\ and José Manuel Guillamón ${ }^{1 *}$ (D)
}

\begin{abstract}
Background: Wine produced at low temperature is often considered to improve sensory qualities. However, there are certain drawbacks to low temperature fermentations: e.g. low growth rate, long lag phase, and sluggish or stuck fermentations. Selection and development of new Saccharomyces cerevisiae strains well adapted at low temperature is interesting for future biotechnological applications. This study aimed to select and develop wine yeast strains that well adapt to ferment at low temperature through evolutionary engineering, and to decipher the process underlying the obtained phenotypes.

Results: We used a pool of 27 commercial yeast strains and set up batch serial dilution experiments to mimic wine fermentation conditions at $12^{\circ} \mathrm{C}$. Evolutionary engineering was accomplished by using the natural yeast mutation rate and mutagenesis procedures. One strain (P5) outcompeted the others under both experimental conditions and was able to impose after 200 generations. The evolved strains showed improved growth and low-temperature fermentation performance compared to the ancestral strain. This improvement was acquired only under inositol limitation. The transcriptomic comparison between the evolved and parental strains showed the greatest up-regulation in four mannoprotein coding genes, which belong to the DAN/TIR family (DAN1, TIR1, TIR4 and TIR3). Genome sequencing of the evolved strain revealed the presence of a SNP in the GAA1 gene and the construction of a site-directed mutant $\left(G A A 7^{\text {Thr } 108}\right.$ ) in a derivative haploid of the ancestral strain resulted in improved fermentation performance. GAA1 encodes a GPI transamidase complex subunit that adds GPI, which is required for inositol synthesis, to newly synthesized proteins, including mannoproteins.
\end{abstract}

Conclusions: In this study we demonstrate the importance of inositol and mannoproteins in yeast adaptation at low temperature and the central role of the GAA1 gene by linking both metabolisms.

Keywords: Wine, Yeast, Experimental evolution, Cold, Fermentation, Inositol

\section{Background}

Low temperatures $\left(10-15{ }^{\circ} \mathrm{C}\right)$ are used in wine fermentations to enhance production and to retain flavor volatiles. In this way, white and "rosé" wines of greater aromatic complexity can be achieved $[1,2]$. However, lowering fermentation temperatures has its disadvantages, including

\footnotetext{
* Correspondence: guillamon@iata.csic.es

'Departamento de Biotecnología de los alimentos, Instituto de Agroquímica y Tecnología de los Alimentos (CSIC), Avda. Agustín Escardino, 7, E-46980 Paterna, Valencia, Spain

Full list of author information is available at the end of the article
}

prolonged process duration and a higher risk of halted or sluggish fermentation [3]. These problems can be avoided by providing better-adapted yeasts to ferment at low temperature. Although the wine industry already has yeasts that are sold as cryotolerant strains, most do not offer desirable fermentation performance at low temperature [4]. Thus, the selection of yeast able to ferment at low temperature is still of much interest for the winemaking industry [5-7]. Nevertheless, regarding low temperature fermentation, natural phenotypic diversity can be very limited in $S$. cerevisiae strains, the least 
psychrotrophic species of the Saccharomyces genus [8]. An appealing alternative is the development of genetically improved new strains of $S$. cerevisiae that are better adapted to grow at low temperature.

In recent decades, many efforts have been made to engineer wine yeast strains with improved characteristics [9-11]. However, metabolic engineering based on recombinant technology has its limitations: 1) requirement for extensive biochemical and genetic information of the metabolism of interest; 2) the complexity of the cellular physiological response, such as activation of an alternative metabolic pathway; 3) cloning difficulties in industrial strains, which result mainly from their genetic complexity; 4) regulatory issues such as using genetically modified organisms (GMO) in the food industry [12]. Nonrecombinant strategies based on evolutionary engineering are attractive because they may generate improved strains that are not considered GMOs, and will most likely be better accepted by the general public. Evolutionary engineering has been used for generating new industrial strains [13-15]. Bioethanol production is the most important area where this approach has been applied in yeast. However, very few studies have reported the development of improved wine yeast strains through evolutionary engineering [16-18].

Experiments for many generations, under conditions to which yeasts are not optimally adapted, help select for more fit genetic variants. Culturing S. cerevisiae populations under long-term selective pressures results in a series of adaptive shifts. These shifts have been observed to occur on the order of once in every 50 generations [19]. The initial (physical or chemical) mutagenesis of the starting culture potentiates increased genetic diversity [20]. Such experiments have also shed light on a bigger question about the molecular basis underlying the improved phenotype. Evolutionary engineering provides the opportunity to study evolutionary adaptation by analyzing either changes in gene expression patterns following adaptive evolution in yeast, or the genome structure and organization or the whole genome sequence of the evolved strains $[21,22,19]$.

The first aim of this study was to assess the most competitive strains that grow under wine fermentation conditions at low temperature. To this end, we performed a growth competition assay with 27 commercial wine strains inoculated at equal population size in synthetic grape must. In spite of the economical and industrial importance of these strains, their phenotypic variation in the main enological traits, particularly those related to optimum growth temperature [8], and their ability to adapt to low temperature fermentation have been poorly investigated. The second goal was to obtain an improved strain to grow and ferment at low temperature by evolutionary engineering. For this purpose, we maintained growth competition in synthetic grape must during 200 generations to select for the mutations that produce phenotypes with improved growth in this medium. One of these evolved cultures was previously treated with ethyl methanesulfonate (EMS) to increase the mutation rate. Finally, we aimed to decipher the molecular basis underlying this improvement by analyzing the genomic and transcriptional differences between the parental strain and the strain evolved at low temperature.

\section{Results}

\section{Competition and adaptive laboratory evolution at low} temperature of a mixed culture of wine yeasts

The growth of batch cultures at $12{ }^{\circ} \mathrm{C}$ was monitored during the whole competition and selection process (Fig. 1). The growth improvement of cultures was evidenced by the continuous increase of the maximum OD $\left(\mathrm{OD}_{\max }\right)$ and the reduction in the generation time (GT) throughout the first 100 generations. No clear growth improvements were observed between 100 and 200 generations, with fluctuations in the $\mathrm{OD}_{\max }$ and $\mathrm{GT}$ values. In any case, the $\mathrm{OD}_{\max }$ value after 200 generations of growth in $\mathrm{SM}$ at $12{ }^{\circ} \mathrm{C}$ was approximately 2 -fold that of $\mathrm{OD}_{\max }$ at the beginning of both the nonmutagenized and mutagenized cultures.

This growth improvement in the serial batch cultures can be explained firstly by the imposition of the most competent strain(s) of the mixed culture, and secondly by the evolution of these strains under selective cold pressure. Monitoring the 27 strains throughout the 200 generations confirmed the first hypothesis (Additional file 1: Figure S1). After 10 generations, only seven and nine strains were detected in the nonEMS and EMS cultures, respectively. Furthermore, major strain P5 already represented more than $50 \%$ in both cultures. Only three strains were detected at generation 50, with P5 representing $57 \%$ and $85 \%$ in the nonmutagenized and mutagenized cultures, respectively. From generation 100 to 200, only strains P5 and P17 were detected in both cultures, and P5 was the major strain with percentages over $90 \%$ at the end of the experiment.

\section{Fermentation performance of evolved strains in different synthetic and natural grape musts}

The fermentation performance of the two strains isolated at the end of the serial batch cultures (P5 and P17) was analyzed. To distinguish between the strains isolated from the non-mutagenized or the mutagenized culture and the parental strains, the evolved strains were complemented with codes -E (evolved without EMS treatment) and EM (evolved and mutagenized), respectively. The fermentation kinetics of the original and evolved strains was estimated by calculating the time needed to ferment $5 \%$ (T5), $50 \%$ (T50) and $100 \%$ (T100) of sugars 


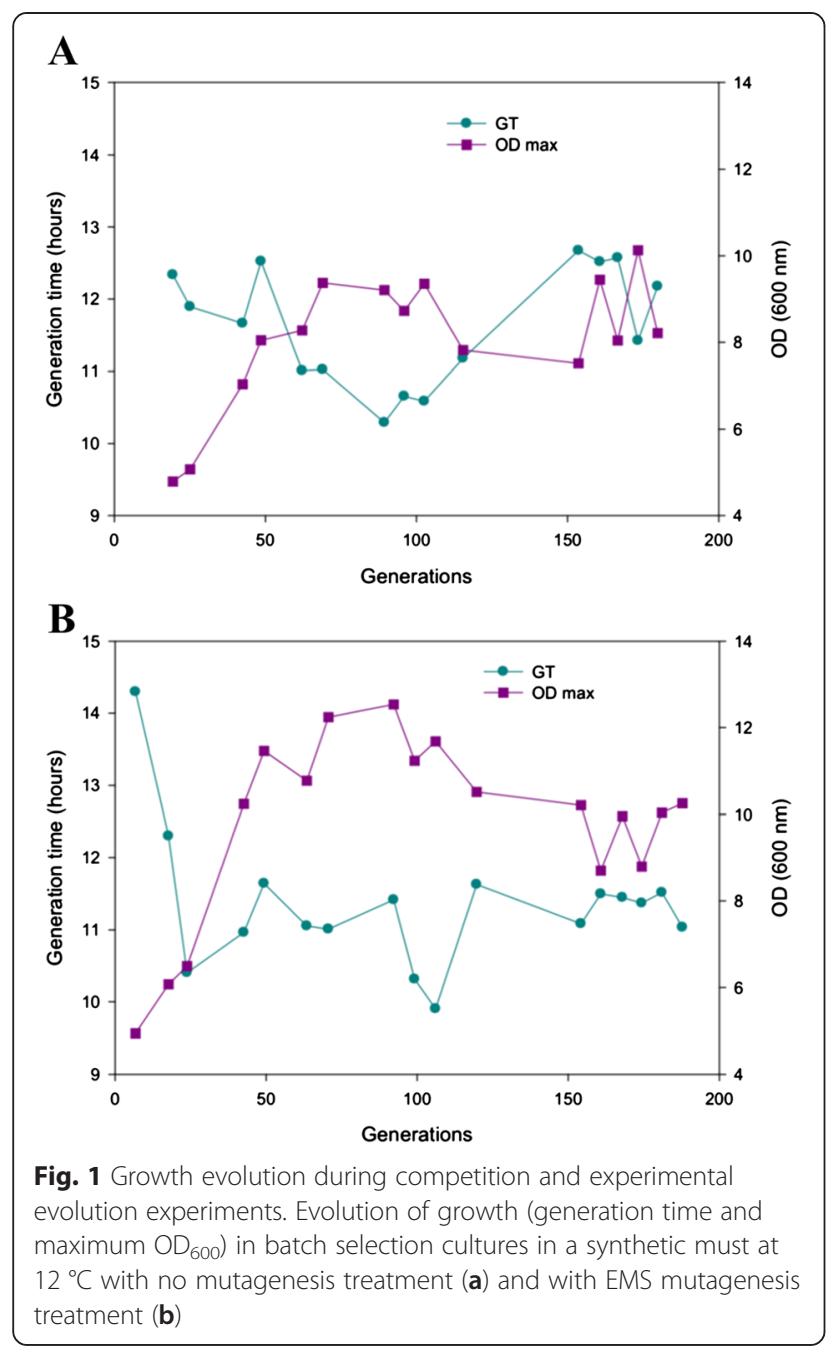

in SM1 (Table 1) and is graphically plotted in Additional file 2: Figure S2. T5, T50 and T100 approximately match the beginning (lag phase), middle (end of exponential phase) and end of fermentation, respectively.

All the evolved strains showed better fermentation performance than the original strains at $12{ }^{\circ} \mathrm{C}$ (Table 1 and
Additional file 2: Figure S2). The most remarkable improvement in the time to complete the low-temperature fermentation was observed in P5-EM. This strain took around $350 \mathrm{~h}$ to finish fermentation, whereas parental strain P5 was unable to consume all the sugars after 30 days $(720 \mathrm{~h})$ of fermentation. Strain P5-EM also reached a maximum OD that was 2-fold higher than original strain P5 (Additional file 2: Figure S2). The other evolved strains, P5-E, P17-E and P17-EM, exhibited similar fermentative behavior, and finished fermentations in more than $500 \mathrm{~h}$. In any case, these three evolved strains also displayed improved fermentation performance and biomass production (higher OD yield) than the parental strains at low temperature (P17 was also unable to consume all the sugars after 30 days). Conversely, these differences in the growth rate and fermentation were absent or minimal during the fermentations at $28^{\circ} \mathrm{C}$.

In an attempt to take a step forward to approach wine industrial conditions, fermentations were carried out with the evolved strains in three natural grape musts (two white grape varieties, "Albariño" and "Macabeo", and one red grape variety, "Garnacha"). Quite surprisingly, we did not observe any differences in fermentation performance between the evolved and parental strains under these conditions (data not shown). These results encouraged us to check the fermentation performance of evolved strain P5-EM at $12{ }^{\circ} \mathrm{C}$ in a new synthetic grape must (SM2), where YNB was replaced with a defined concentration of mineral salts and vitamins (Additional file 3: Figure S3A). As in the natural grape musts, no differences in both fermentation rate and biomass production were observed between the original and evolved strains.

\section{Determining the limiting nutrient at low temperature in SM1}

The different fitness noted between the parental and evolved strains observed in SM1, but not in SM2, should be explained by the presence of a limiting nutrient

Table 1 Determination of the time required by the evolved and original strains to ferment $5 \%$ (T5), $50 \%$ (T50) and 100\% (T100) of the initial sugar content in a synthetic must $(\mathrm{SM} 1)$ at $12{ }^{\circ} \mathrm{C}$ and $28^{\circ} \mathrm{C}$

\begin{tabular}{|c|c|c|c|c|c|c|}
\hline Strain & P5 & P5-E & P5-EM & P17 & P17-E & P17-EM \\
\hline \multicolumn{7}{|l|}{$28^{\circ} \mathrm{C}$} \\
\hline T5 (h) & $6.30 \pm 0.74$ & $5.98 \pm 0.81$ & $10.04 \pm 0.81^{*}$ & $7.71 \pm 0.90$ & $9.96 \pm 1.83$ & $9.28 \pm 0.34^{*}$ \\
\hline T50 (h) & $38.54 \pm 0.74$ & $38.54 \pm 2.25$ & $37.7 \pm 0.98$ & $50.39 \pm 2.05$ & $48.93 \pm 1.55$ & $48.14 \pm 0.90$ \\
\hline T100 (h) & $127.38 \pm 3.43$ & $126.31 \pm 5.64$ & $89.47 \pm 11.84^{*}$ & $147.27 \pm 3.98$ & $125.29 \pm 21.15$ & $149.7 \pm 0.00$ \\
\hline \multicolumn{7}{|l|}{$12^{\circ} \mathrm{C}$} \\
\hline T5 (h) & $29.625 \pm 3.25$ & $20.81 \pm 0.80^{*}$ & $22.88 \pm 2.60^{*}$ & $65.74 \pm 5.21$ & $64.61 \pm 4.27$ & $54.09 \pm 9.63$ \\
\hline T50 (h) & $211.88 \pm 48.94$ & $172.88 \pm 47.43$ & $104.63 \pm 8.11^{*}$ & $335.83 \pm 14.39$ & $203.98 \pm 9.82^{*}$ & $210.36 \pm 9.04^{*}$ \\
\hline $\mathrm{T} 100$ (h) & - & $505.69 \pm 97.85^{*}$ & $349.13 \pm 68.85^{*}$ & - & $539.43 \pm 5.21^{*}$ & $570.1 \pm 8.46^{*}$ \\
\hline
\end{tabular}

*Statistically significant differences $(P$-value $\leq 0.05)$ compared with their control strain at the same temperature - Unfinished fermentation 
(vitamin or mineral salt) or inhibitor (potassium disulfite) in this medium, and the evolution process had adapted strains to overcome this limitation/inhibition. It should be borne in mind that the evolution process was performed in the SM1 medium. In order to determine the limiting nutrient in SM1 at $12{ }^{\circ} \mathrm{C}$, we carried out the fermentations of P5 and P5-EM using SM1 amended with every single compound that varied between both synthetic musts (Additional file 4: Table S1). The limiting nutrient was determined as inositol because we observed a recovered phenotype of the parental strain when inositol was added at the same concentration as in SM2 (Additional file 3: Figure S3B). Remarkably, addition of only inositol to SM1 resulted in the same fermentation and growth performance between both strains, and the fitness advantage of P5-EM disappeared (Fig. 2). Moreover, the $\mathrm{OD}_{\max }$ at $12{ }^{\circ} \mathrm{C}$ of the parental strain correlated positively with an increasing inositol concentration (OLS regression slope: $0.465, \mathrm{R}^{2}: 0.893$, Pvalue $<0.001$ ), whereas the evolved strain $\mathrm{OD}_{\max }$ correlated negatively with an increasing inositol concentration (OLS regression slope: $-0.221, \mathrm{R}^{2}: 0.754$, P-value $<0.001$ ) (Fig. 3).

\section{The transcriptomic analysis of evolved strain P5-EM highlighted the strong up-regulation of mannoprotein genes}

The global gene expression of P5-EM was analyzed during the SM1 fermentation at $12{ }^{\circ} \mathrm{C}$ and compared with its parental strain P5. The physiological condition chosen for analyzing the gene expression was the midexponential growth phase $(96 \mathrm{~h})$. The comparative results of the transcriptional profiles revealed that only $2.6 \%(161 / 6124)$ of yeast genes showed significant differences in the transcript levels of at least 2-fold (Additional file 5: Table S2). Of these, 107 genes displayed a reduced expression in the evolved strain compared to the parental one, whereas only 54 genes exhibited an increased expression in P5-EM.

A MIPS categories analysis was done with the up- and down-regulated genes (Additional file 6: Table S3). The largest percentage of the up-regulated genes in P5-EM belonged to the functional category "metabolism" (40\%) and the sub-category "C-compound and carbohydrate metabolism" (22\%). Among the down-regulated genes, functional categories "transcription" and "protein with binding function or cofactor requirement" gave the largest percentages of genes ( $29.90 \%$ and $24.29 \%$, respectively).

When we focused on the most strongly up-regulated genes in P5-EM (Fig. 4a), four belonged to the DAN/TIR family (DAN1, TIR1, TIR4 and TIR3), which are cell wall mannoprotein genes, widely linked to a low temperature response [23]. HPF1, which encodes a mannoprotein that performs protective functions against protein
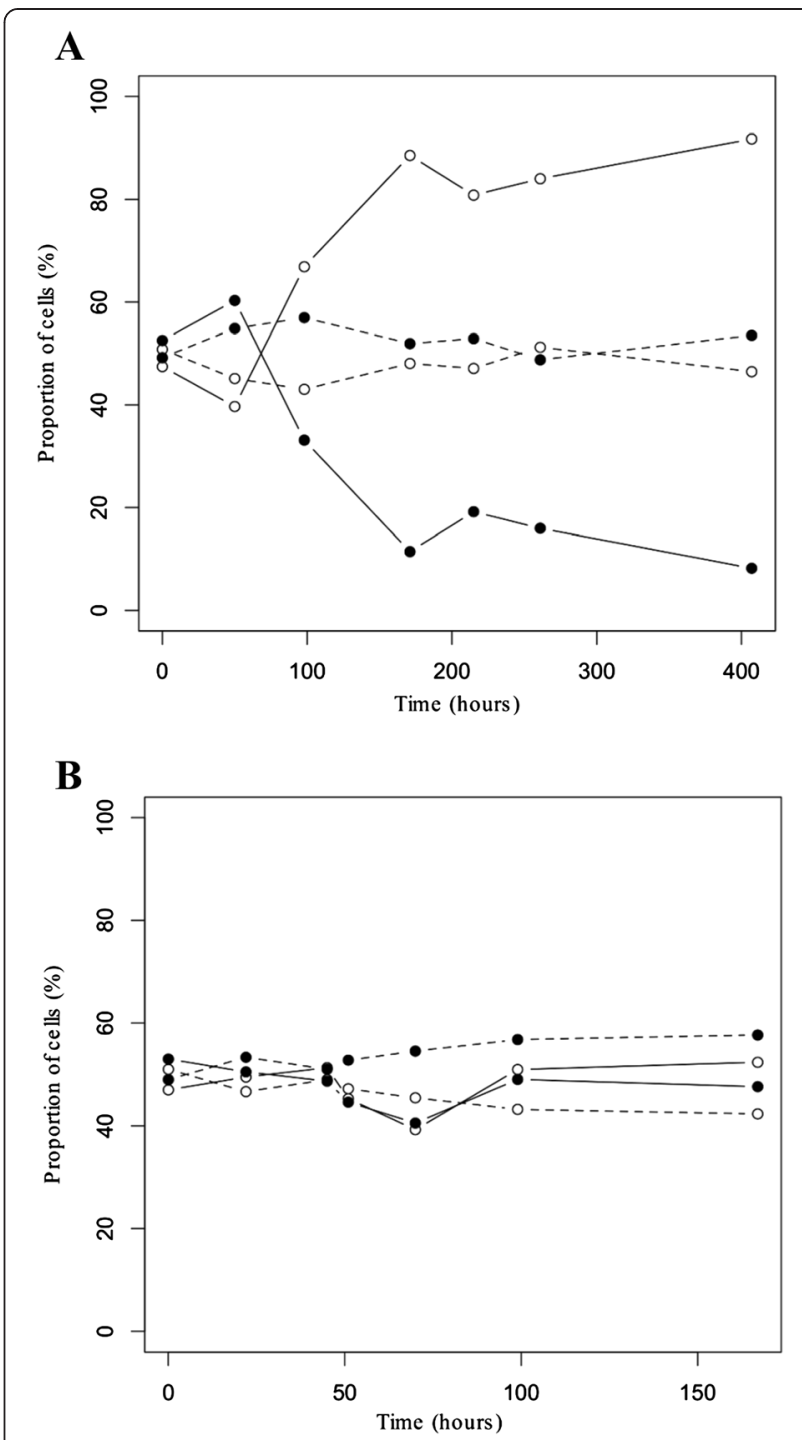

Fig. 2 Population dynamics of P5 and P5-EM in SM1 and SM1+1 musts. Cell percentages of P5 (filled circles) and P5-EM (open circles) during the competition fermentations in SM1 (solid lines) and SM1 + inositol (20 mg/L) (dashed lines) at $12{ }^{\circ} \mathrm{C}$ (a) and $28^{\circ} \mathrm{C}(\mathbf{b})$

aggregation in wines [24], also appeared among these top-ten up-regulated genes. The highest down-regulated genes (Fig. 4b) were: SFC1 (encodes a mitochondrial succinate-fumarate transporter); GIT1 (encodes a plasma membrane permease that mediates the uptake of glycerophosphoinositol and glycerophosphatidylcholine); and PUT1 (encodes proline oxidase).

\section{Metabolic changes in mannoprotein content and lipid composition}

As the transcriptomic analysis revealed this strong upregulation of several mannoprotein genes, the amount of extracellular and cellular mannoproteins was determined during the fermentations of SM1 and SM1 supplemented 

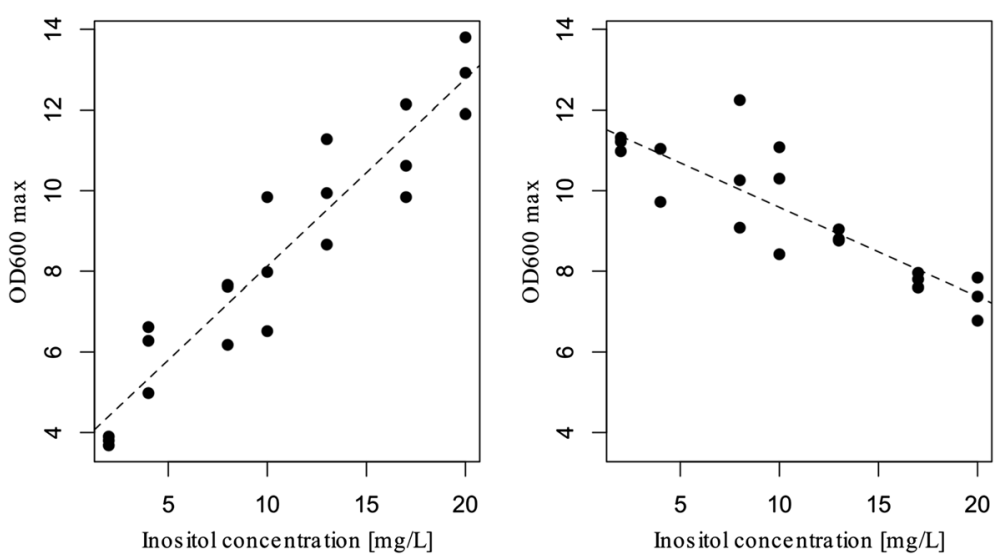

Fig. 3 Relation between inositol concentration and maximum $\mathrm{OD}_{600 \mathrm{~nm}}$. Maximum $\mathrm{OD}_{600 \mathrm{~nm}}$ of P5 (left panel) and P5-EM (right panel) during the fermentations at $12{ }^{\circ} \mathrm{C}$ in SM1 and SM1 amended with different inositol concentrations. The line represents linear regression

with inositol $(\mathrm{SM} 1+\mathrm{I})$ at $28{ }^{\circ} \mathrm{C}$ and $12{ }^{\circ} \mathrm{C}$ respectively (Fig. 5 and Table 2). Evolved strain P5-EM released more mannoproteins to the growth medium because the wines fermented with this strain presented higher mannoprotein content, regardless of temperature. However, the greatest

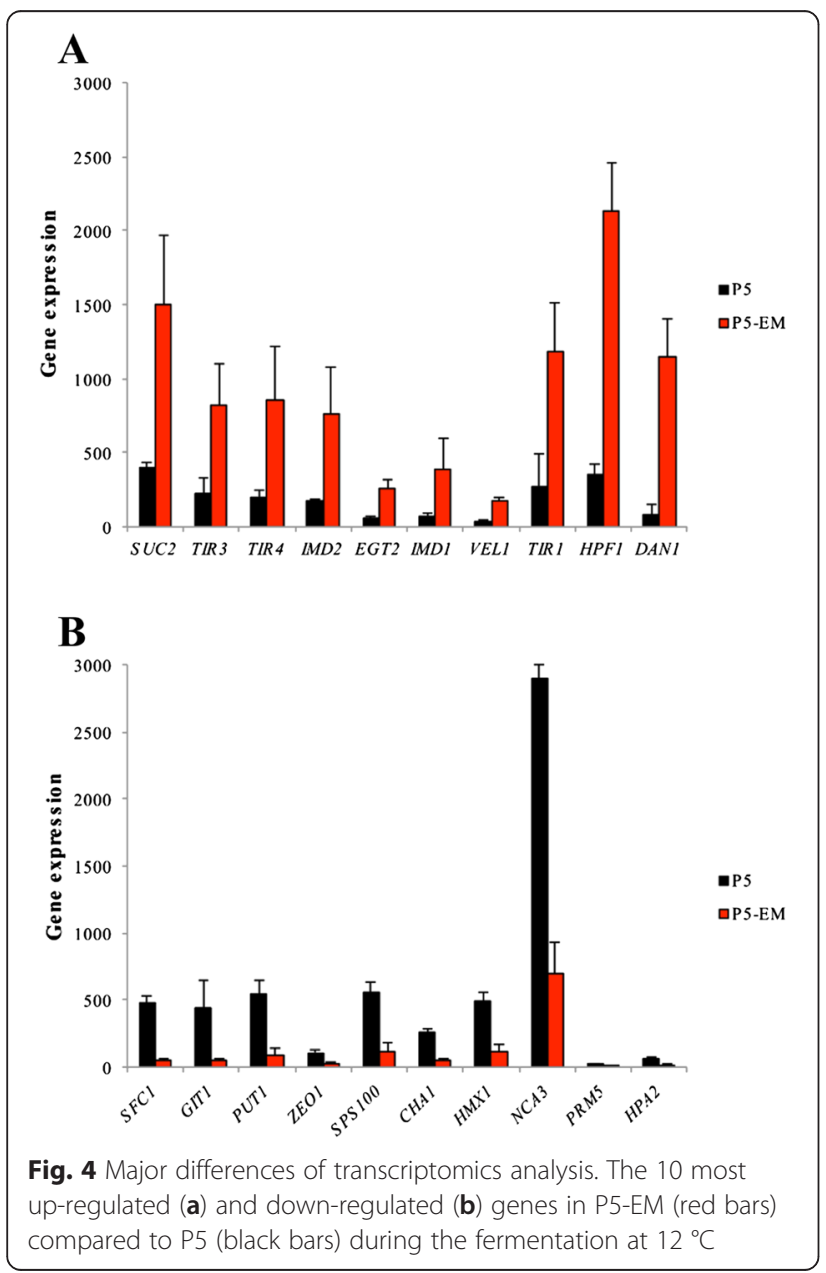

increase in mannoprotein content occurred with the enrichment of synthetic grape must with inositol. The final SM1 + I wines had mannoprotein concentrations of around 2- and 3-fold more than the SM1 wines. It is noteworthy that the cellular mannoprotein content (Table 2) correlated negatively with content in wines (Fig. 5). The strains grown in the inositol-limited medium (SM1) obtained a higher cellular concentration than the cells grown in excess inositol $(\mathrm{SM} 1+\mathrm{I})$. Evolved strain P5-EM also showed higher cellular concentrations than parental strain P5.

Likewise, the phospholipid composition of the parental and evolved strains was also determined during fermentation in both media with limited and excess inositol. The percentage of the main phospholipid classes and their distribution in the different molecular species (phospholipid molecules varying in length and number of double bonds) are shown in Tables 3 and Additional file 7: Table S4, respectively. In order to highlight the most important changes between strains, temperature and fermentation medium according to their phospholipid composition, a Principal Component Analysis (PCA) was performed on the 24 individual samples

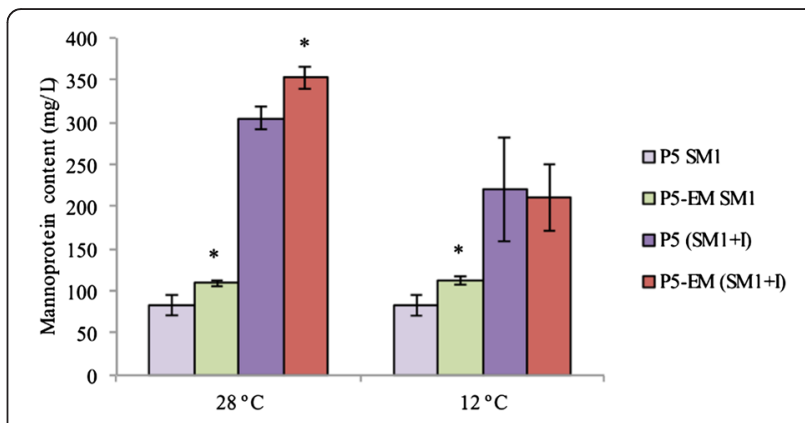

Fig. 5 Mannoprotein content. Final concentrations of mannoprotein ( $\mathrm{mg} / \mathrm{L}$ ) released by $\mathrm{P} 5$ and $\mathrm{P} 5$-EM during the fermentation at $28{ }^{\circ} \mathrm{C}$ and $12{ }^{\circ} \mathrm{C}$ in SM1 and SM1 + inositol (20 mg/L) 
Table 2 Mannoprotein content in cell wall yeast (mg mannoprotein/g dry weight (DW)) in the mid-exponential growth phase $\left(24 \mathrm{~h}\right.$ at $28^{\circ} \mathrm{C}$ and $96 \mathrm{~h}$ at $\left.12^{\circ} \mathrm{C}\right)$ during fermentation in SM1 and SM1 + Inositol (20 mg/L)

\begin{tabular}{lll}
\hline Strain & P5 & P5-EM \\
\hline $\mathbf{2 8}{ }^{\circ} \mathbf{C}(\mathbf{2 4} \mathbf{h})$ & & \\
$\mathrm{SM} 1$ & $192.68 \pm 25.16$ & $221.24 \pm 16.79^{*}$ \\
$\mathrm{SM} 1+\mathrm{I}$ & $145.87 \pm 30.96$ & $140.22 \pm 13.63$ \\
$\mathbf{1 2}{ }^{\circ} \mathbf{C}(\mathbf{9 6} \mathbf{h})$ & & \\
$\mathrm{SM} 1$ & $199.65 \pm 8.76$ & $264.68 \pm 36.63^{*}$ \\
$\mathrm{SM} 1+\mathrm{I}$ & $124.64 \pm 9.10$ & $158.23 \pm 14.80^{*}$ \\
\hline
\end{tabular}

obtained (2 strains x 2 temperatures x 2 SM x 3 triplicates) (Fig. 6). The two first components were retained and explained $91.6 \%$ of total variance. The first component explained $80.3 \%$ of variance and was marked by high positive component loadings for PC (34:2) (+0.77) and PC (32:2) (+0.38). The second component explained $11.3 \%$ of variation and was marked by positive components loadings for PI (34:1) (+0.38) and PI (36:1) (+0.35), and by high negative loadings for PC (34:1) (-0.56) and PC (32:1) (-0.36). The general ordination of the samples by PCA showed the formation of two groups along the first axis: SM1, associated with high values of PC (34:1) and PC (32:1); SM1 + I, associated with high values of PI (34:1) and PI (36:1). Within the SM1 + I group, another separation was observed due to temperature. Lowtemperature samples were associated with high values of PC (34:2) and PC (32:2). A similar pattern was observed within the SM1 group, but the P5 samples at $12{ }^{\circ} \mathrm{C}$ were grouped with the $28{ }^{\circ} \mathrm{C}$ samples.

\section{Changes in the genome of evolved strain P5-EM in com- parison to parental strain P5: reconstruction of mutation GAA1 ${ }^{\text {Thr108 }}$}

The whole genome of evolved mutant P5-EM was sequenced and compared with that of parent strain P5. We identified 18 single nucleotide polymorphisms (SNPs) in the P5-EM genome. Eight of these SNPs were nonsynonymous in the coding regions of eight genes (Table 4). Only one SNP, found in the ODC2 gene, involved a change in regulatory sequence $5^{\prime}$ upstream of the ORF.

Several of the above-mentioned results indicated that the SNP in GAA1 might explain the phenotypic differences observed between P5-EM and P5. This gene encodes a subunit of the GPI-protein transamidase complex, required to attach glycosylphosphatidylinositol (GPI) to the proteins in the ER, a mechanism by which proteins are attached to the cell surface in all eukaryotic cells. To check the relevance of this mutation, we constructed a site-directed mutant in GAA1 to GAA1 Thr108 in a derivative haploid of parental strain P5. We analyzed the fermentation performance of P5 GAA1 $1^{\text {Thr108 }}$ at $12{ }^{\circ} \mathrm{C}$ and $28{ }^{\circ} \mathrm{C}$, which was compared with derivative haploid P5.

The fermentation kinetics of both strains was estimated by calculating the time needed to ferment $5 \%$ (T5), $25 \%$ (T25), $50 \%$ (T50), $75 \%$ (T75) and $100 \%$ (T100) of the sugars in SM1. As previously observed for parental strain $\mathrm{P} 5$, its haploid was also unable to finish fermentation at $12{ }^{\circ} \mathrm{C}$, whereas P5 GAA1 Thr108 completed fermentation. The percentage of improvement at T5, T25, T50 and T75 during the fermentation at $12{ }^{\circ} \mathrm{C}$ of P5 GAA1 $1^{\text {Thr108 }}$ and P5-EM, in comparison to their respective parental strains, is plotted graphically in

Table 3 Percentage of phospholipids (LysoPC, PC, LysoPE, PE, PI, PS, PA and PG) expressed as the mean \pm SEM (standard error of the mean) of total cellular concentration of these compounds. Cellular concentration of total phospholipid (Total PL) expressed as nmol/ mg of dry weight. Significant differences (P $\leq 0.05$ ), bold letters, was examined with $t$-test and was compared P5-EM with P5 strain in each condition

\begin{tabular}{|c|c|c|c|c|c|c|c|c|}
\hline & \multicolumn{4}{|l|}{ SM1 } & \multicolumn{4}{|l|}{ SM1 + Inositol } \\
\hline & \multicolumn{2}{|l|}{$28^{\circ} \mathrm{C}$} & \multicolumn{2}{|l|}{$12^{\circ} \mathrm{C}$} & \multicolumn{2}{|l|}{$28^{\circ} \mathrm{C}$} & \multicolumn{2}{|l|}{$12^{\circ} \mathrm{C}$} \\
\hline & P5 & P5-EM & $\mathrm{P} 5$ & P5-EM & P5 & P5-EM & P5 & P5-EM \\
\hline Total LysoPC & $4.33 \pm 0.65$ & $3.50 \pm 0.19$ & $3.67 \pm 2.09$ & $2.05 \pm 0.31$ & $1.04 \pm 0.45$ & $2.85 \pm 0.06$ & $1.79 \pm 0.24$ & $1.75 \pm 0.30$ \\
\hline Total PC & $51.32 \pm 1.59$ & $49.82 \pm 1.35$ & $53.14 \pm 1.72$ & $53.64 \pm 2.23$ & $32.35 \pm 3.28$ & $44.89 \pm 3.09$ & $46.90 \pm 3.44$ & $49.44 \pm 0.24$ \\
\hline Total LysoPE & $3.16 \pm 0.46$ & $2.17 \pm 0.08$ & $1.71 \pm 0.24$ & $1.16 \pm 0.09$ & $0.98 \pm 0.20$ & $1.68 \pm 0.03$ & $1.23 \pm 0.07$ & $1.04 \pm 0.08$ \\
\hline Total PE & $18.29 \pm 0.14$ & $16.15 \pm 0.57$ & $21.99 \pm 0.85$ & $18.81 \pm 1.10$ & $15.12 \pm 3.99$ & $15.52 \pm 0.15$ & $19.86 \pm 0.17$ & $16.75 \pm 0.17$ \\
\hline Total PI & $9.49 \pm 1.60$ & $16.77 \pm 1.16$ & $8.36 \pm 0.57$ & $17.42 \pm 3.28$ & $40.42 \pm 2.99$ & $29.21 \pm 3.70$ & $24.25 \pm 4.47$ & $27.11 \pm 0.82$ \\
\hline Total PS & $5.21 \pm 0.89$ & $5.06 \pm 0.47$ & $2.66 \pm 0.23$ & $3.06 \pm 0.36$ & $7.49 \pm 3.86$ & $2.27 \pm 0.92$ & $3.80 \pm 0.78$ & $1.82 \pm 0.58$ \\
\hline Total PA & $6.70 \pm 0.37$ & $5.60 \pm 0.27$ & $5.91 \pm 0.33$ & $2.97 \pm 1.00$ & $1.64 \pm 0.33$ & $3.21 \pm 0.50$ & $1.52 \pm 0.11$ & $1.65 \pm 0.10$ \\
\hline Total PG & $1.49 \pm 0.65$ & $0.92 \pm 0.07$ & $2.56 \pm 0.16$ & $0.88 \pm 0.25$ & $0.96 \pm 0.58$ & $0.38 \pm 0.05$ & $0.65 \pm 0.10$ & $0.44 \pm 0.07$ \\
\hline Total PL & $25,81 \pm 1.00$ & $23.36 \pm 4.40$ & $15.75 \pm 2.43$ & $32.44 \pm 6.37$ & $7.98 \pm 5.51$ & $23.81 \pm 3.51$ & $28.55 \pm 1.98$ & $35.44 \pm 2.32$ \\
\hline
\end{tabular}




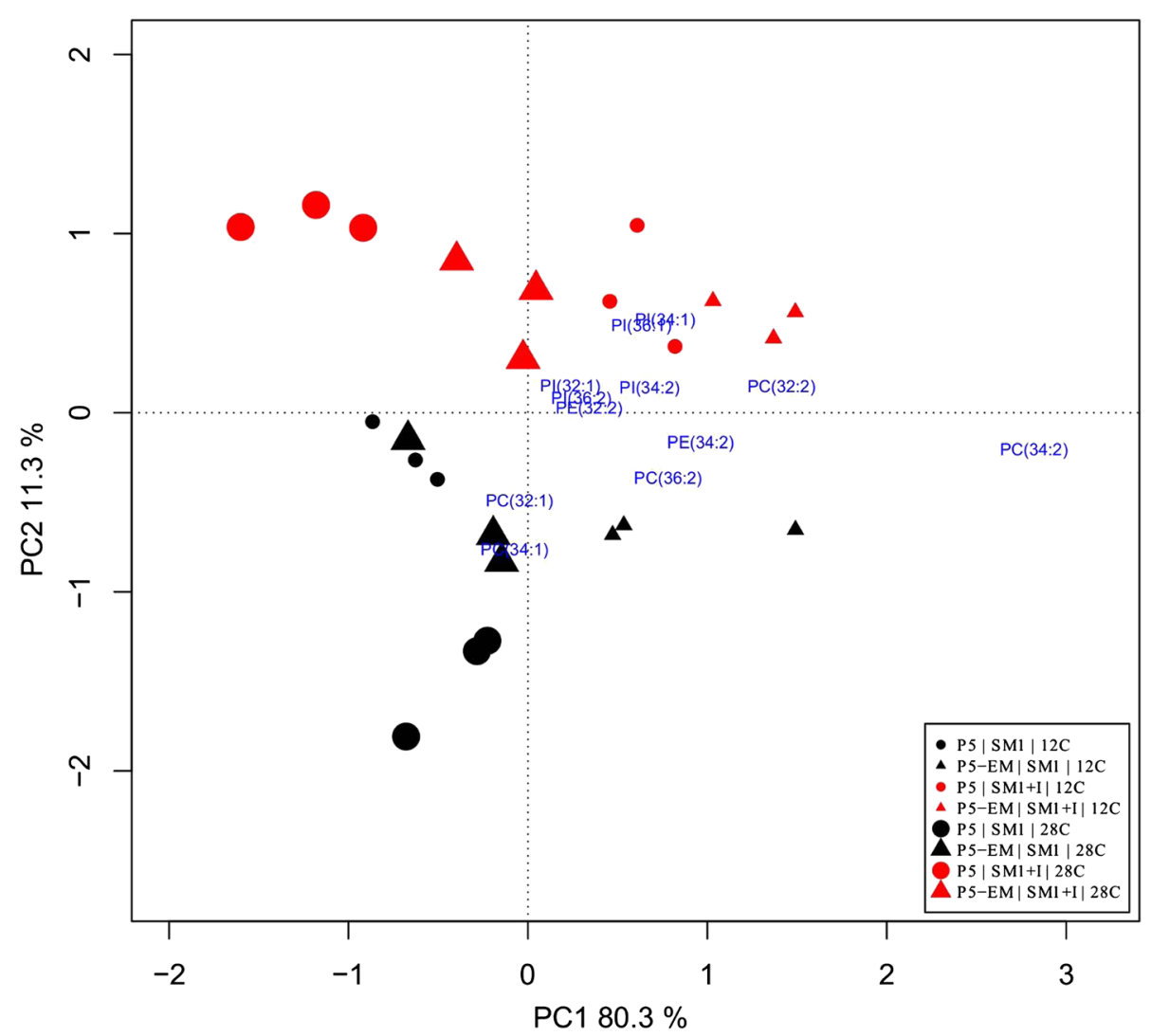

Fig. 6 Principal component analysis of lipid composition. Biplot of the first two PCA components according to the lipid composition of strains P5 and P5-EM during the fermentations at $28^{\circ} \mathrm{C}$ and $12{ }^{\circ} \mathrm{C}$ in SM1 and SM1 + inositol $(20 \mathrm{mg} / \mathrm{L})$

Figure 7. The results showed that P5-EM improved $50 \%$ at T75, whereas the only mutation in GAA1 ${ }^{\text {Thr108 }}$ resulted in a $10 \%$ improvement at $\mathrm{T} 75$, demonstrating that other mutations in addition to GAA1 $1^{\text {Thr108 }}$ are required to explain all of the improvement in fermentation in the evolved strain. At $28{ }^{\circ} \mathrm{C}$, only strain P5-EM showed a slight improvement at T75 (Additional file 8: Figure S4). At the remaining time points analyzed at $28^{\circ}$ $\mathrm{C}$, the parental strain mostly performed better than P5EM and P5 GAA1 ${ }^{\text {Thr108. }}$.

\section{Discussion}

In this study we used a batch serial dilution in a context that mimicked wine fermentation conditions at $12{ }^{\circ} \mathrm{C}$ to perform a competition experiment and experimental evolution. With this strategy, we attempted to select the most competent strains during the first generations, whereas longer exposure to low temperature led to an evolutionary adaptation of the genome of the previously selected strain/s. Monitoring strain diversity revealed that strain P5 was extremely competent very early in

Table 4 Nonsynonymous single nucleotide polymorphisms (SNPs) identified in the coding regions in strain P5-EM in comparison to the parental strain (P5)

\begin{tabular}{llllllll}
\hline Chr & Coordinate & Ref. & Mut. & Change & Het/Hom & Gene & Molecular function \\
\hline IV & 119953 & G & A & S547F & het & UFD2 & ubiquitin-ubiquitin ligase activity \\
IV & 974831 & C & T & E318K & het & YAP6 & sequence-specific DNA binding RNA polymerase II transcription factor activity \\
IX & 108277 & C & T & G1654D & het & TAO3 & component of the RAM signaling network (molecular_function unknown) \\
V & 143758 & C & T & H623Y & het & MIT1 & transcriptional regulator of pseudohyphal growth (molecular_function unknown) \\
XII & 316429 & C & T & T108I & het & GAA1 & contributes to GPI-anchor transamidase activity \\
XIII & 257816 & G & A & P201S & het & GIS4 & CAAX box containing protein of unknown function \\
XIV & 128913 & C & T & D58N & hom & SEC2 & guanyl-nucleotide exchange factor activity \\
XV & 848746 & C & T & T90I & het & HUA2 & cytoplasmic protein of unknown function \\
\hline
\end{tabular}




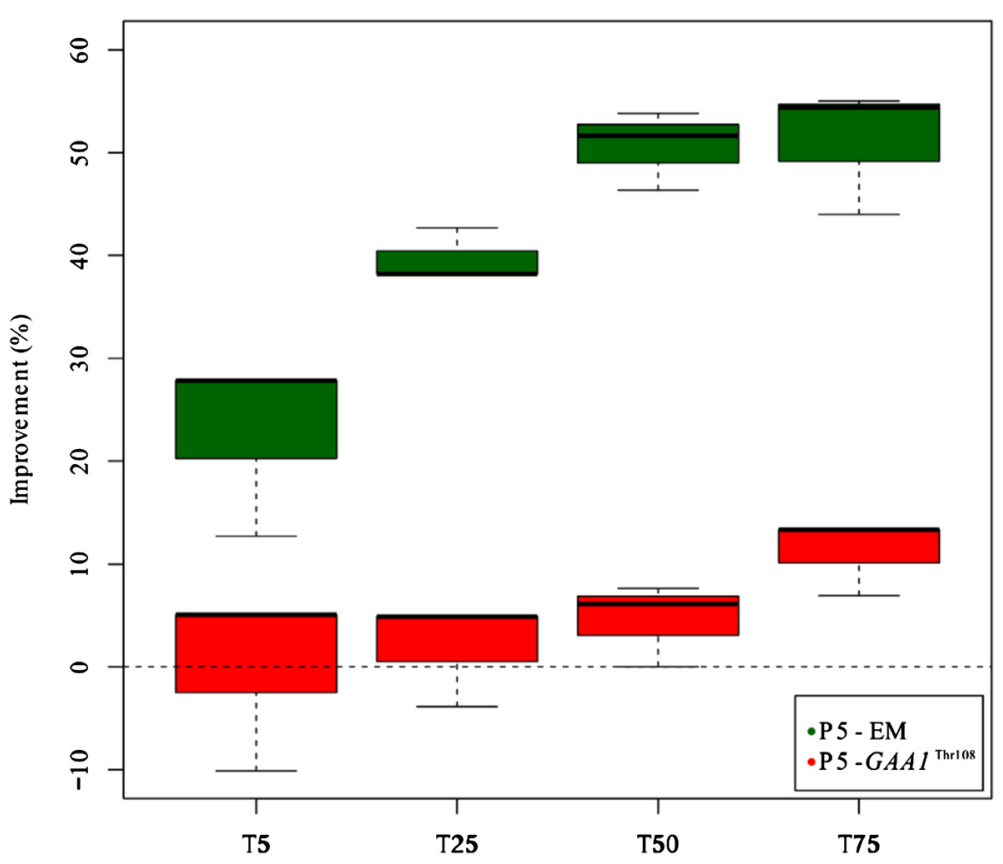

Fig. 7 Dynamics of improvement in fermentation performance at $12{ }^{\circ} \mathrm{C}$. Percentage of improvement in the fermentation kinetics at $12{ }^{\circ} \mathrm{C}(T 5$, T25, T50 and T75) of P5-EM and P5 GAA $7^{\text {Thr } 108}$ compared to P5, and a derivative haploid of P5 GAA1, respectively

serial batch cultures. The mutational changes that led this strain to better adapt to low temperature fermentations were also denoted by improvements in growth parameters during the first 100 generations of the serial batch cultures. Subsequently, the fermentation test carried out in the same medium used for the evolution experiment confirmed the genetic improvement of this strain to grow and ferment at low temperature. However, it proved somewhat disappointing when we checked that this improvement in the growth and fermentation rates only happened in the context of the selection medium (SM1). We used YNB in this medium to provide the microelements (mineral salts and vitamins) needed for yeast growth and found the higher demand for inositol to grow at low temperature converted this vitamin into a growth-limiting substrate. Inositol is an essential phospholipid precursor in yeast cells and could be incorporated into phosphatidylinositol (PI), sphingolipids and glycosylphosphatidylinositol anchors [25]. It is known that phospholipid composition plays an essential role in adaptation to low-temperature fermentations [26]. Therefore, our results evidenced that evolved strain P5EM has a fitness advantage in this inositol limitation context at low temperature. This advantage was lost in excess inositol or at an optimum temperature. Steensels et al. [27] previously stressed the importance of selection conditions matching the industrial parameters as closely as possible and, concerning to inositol content, SM1 did not show enough resemblance with natural grape must. In spite of this unexpected result, the strategy followed in this study provides evidence for the utility of competition experiments for detecting the most competitive strains among a pool of commercial strains, as well as evolutionary engineering as a nonrecombinant technique to isolate the commercial wine yeast strains that are highly tailored to stressful low-temperature wine fermentation conditions. In industrial settings, cells often face combinations of different stresses [28]. During wine fermentations, for example, cells encounter osmotic stress, high ethanol levels and nutrient deprivation. Through selection steps under conditions that resemble this harsh environment, researchers have succeeded in improving wine strains by evolutionary engineering [16-18].

Apart from the importance of obtaining improved strains to be used during wine fermentations in industry, another important aim of this study was to detect the physiological and molecular bases underlying this improved phenotype. For this purpose, metabolic, transcriptomic and genomic changes in evolved strain P5EM were determined in comparison to parental strain P5. As mentioned above, our results clearly provide evidence for a higher demand for inositol when cells grew at low temperature. However the evolved strain was able to bypass this inositol requirement, to the extent that a negative correlation between inositol concentration and growth of this strain was observed. Wenger et al. [29] formerly reported that organisms adaptively evolved in limiting-nutrient environments perform worse than their ancestors in some cases when resources are nonlimiting. 
These trade-offs may result from either the adaptive mutations themselves or the accumulation of conditional loss-of-function mutations elsewhere in the genome.

Incubation at low temperature increases the molecular order of membrane lipids by rigidification [30]. Yeast responds to this rigidification by adapting different changes in the membrane lipid composition to maintain appropriate membrane fluidity. Nevertheless, inositol limitation denoted incapacity to reshape its lipid composition in the parental P5 strain. The inositol used in the synthesis of PI is either produced from glucose-6phosphate or imported from the culture medium. Thus the fitness advantage observed in the evolved strain could potentially be explained by the optimization of the synthesis route to counteract the limitation of inositol in the culture medium. However we detected neither transcriptomic difference nor genomic changes in the genes involved in inositol biosynthesis or transport. The only likely exception was the strong down-regulation of GIT1 observed in the evolved strain. This gene encodes a plasma membrane permease that mediates the uptake of glycerophosphoinositol and glycerophosphocholine as a source of inositol and phosphate [31,32]. The lower inositol requirement of this strain could lead to down regulation of a gene involved in the transport of compounds that can be used as inositol sources. Yet, regardless of the direct involvement of inositol in the synthesis of PI, we should bear in mind its crucial role in the transcriptional regulation of many phospholipid biosynthesis genes [33]. The general impact of inositol on phospholipid biosynthesis was revealed by the differences found in the total phospholipid content in strain P5 growing at low temperature (almost 2-fold more in SM1 + I than in SM1; Table 3). Somehow the evolved strain is not subjected to this tight regulation by inositol because this strain showed similar phospholipid content when grown at low temperature in both media.

Another metabolic change in the evolved strain was the increase noted in extracellular and intracellular mannoprotein contents. These mannoproteins are attached to the cell wall via glycosilphosphatidylinositol (GPI) moieties, and are essential for cell wall integrity [34] and cell viability [35]. The GPI anchor is synthesized from PI through multiple steps in the ER and it is then transferred to the $\mathrm{C}$ terminus of proteins bearing a GPI attachment signal sequence. GAA1 encodes a subunit of the GPI-protein transamidase complex, which is required for the attachment of a completed GPI anchor to proteins [36]. We have shown how the introduction of allele $G A A 1^{\text {Thr108 }}$, detected in the evolved strain, into the parental strain represents a $10 \%$ improvement in fermentation time. This single point-mutation can partially explain the improved fermentation behavior observed in the evolved strain at low temperature.
Obviously, this SNP was unable to completely reproduce the fermentation improvement observed in the evolved strain, which indicates the existence of other genetic determinants of cold adaptation. The results presented herein provide valuable additional genes, which can be used as a starting point for future efforts to disentangle the genetic basis of low temperature adaptation.

Regardless of the possible connection between the deficient synthesis of GPI-anchored proteins and a lower fitness at low temperature, our results suggested the direct involvement of mannoproteins in cold adaptation. The overexpression of the mannoprotein genes in the evolved strain was related with increased mannoprotein content in the cell wall and an increase in the mannoprotein released at the end of fermentation. The induction of a subset of DAN/TIR genes has been previously related to hypoxia, high pressure and low temperature conditions $[37,23,38]$. In a recent work, we also detected that the overexpression of TIP1 and TIR2 improved fermentation activity and growth at $12{ }^{\circ} \mathrm{C}$ [39]. Abramova et al. [23] postulated that this adaptation event is related either to membrane fluidity and affects membrane properties, or, some of these proteins play a role in sterol transport.

Further indirect molecular evidence for the better fitness of the evolved strain at low temperature was the up-regulation of functional categories, such as " $\mathrm{C}$-compound and carbohydrate metabolism" and "cytokinesis (cell division)/septum formation and hydrolysis", which can explain the higher fermentation and growth rates observed in this strain. In order to find out other experimental situations that provoke a similar gene expression response to that obtained in this study, we used the SPELL tool via the Saccharomyces Genome Database (SGD) [40]. Interestingly, the datasets from published microarray experiments, whose expression profiles most closely resemble our data, dealt with the impact of mannose and inositol pyrophosphate on carbon utilization, protein glycosylation and environmental stress response [41, 42]. This result provided additional support for a correlation between transcriptomic data and inositol and mannoprotein metabolism.

\section{Conclusions}

Our data provide clear evidence for the greater requirement for inositol for $S$. cerevisiae growth at low temperature. We evolved a commercial wine strain in an inositol-limiting environment at low temperature. Both the growth capacity and fermentation activity of this strain improved at low temperature, and showed clear physiological and molecular changes in comparison with its parental strain. The capacity to reshape its membrane lipid composition and a better mannoprotein synthesis capacity seemed to be paramount for this strain's cold 
adaptation. The mutation observed in gene GAA1, involved in the synthesis of the GPI-anchored proteins, partially explained the improvement observed in the evolved strain. We also provide a short list of candidate genes for further exploration in the search for mechanisms involved in low-temperature adaptation in industrial yeasts.

\section{Methods}

\section{Strains and mutagenesis}

A pool of 27 commercial wine yeast strains was used in this study. The industrial strains were kindly provided by Lallemand Inc. (France) and were typed by their interdelta sequences [43], thus they were named according to their delta pattern (from P1 to P27). Their corresponding commercial names are shown in Additional file 9: Table S5 and their enological features can be obtained from the company's website (http://www.lallemandwine.com). Before chemical mutagenesis, the yeast cells of each strain were grown overnight in $3 \mathrm{~mL}$ of YPD at $30{ }^{\circ} \mathrm{C}$ and $200 \mathrm{rpm}$. A mixed culture with the same proportion of each strain was prepared to a final cell concentration of $2 \times 10^{8}$ cells $/ \mathrm{mL}$. This mixed culture was divided into two lots: one was mutagenized with EMS, following the protocol described by Winston [44], and the other was used as a nonmutagenized control. Both mutagenized and nonmutagenized cultures were further used as inocula of the competition and evolution experiments.

\section{Competition experiments and experimental evolution}

After mutagenesis procedures, cells were transferred to a chemically defined synthetic grape must (SM1), recently described by Quirós et al. [45]. The SM1 composition included $200 \mathrm{~g} / \mathrm{L}$ of sugars $(100 \mathrm{~g} / \mathrm{L}$ glucose $+100 \mathrm{~g} / \mathrm{L}$ fructose), $6 \mathrm{~g} / \mathrm{L}$ of malic acid, $6 \mathrm{~g} / \mathrm{L}$ of citric acid, $1.7 \mathrm{~g} / \mathrm{L}$ of YNB without ammonium and amino acids, anaerobic factors $(15 \mathrm{mg} / \mathrm{L}$ ergosterol, $5 \mathrm{mg} / \mathrm{L}$ sodium oleate and $0.5 \mathrm{~mL} / \mathrm{L}$ tween 80 ) and $60 \mathrm{mg} / \mathrm{L}$ of potassium disulfite. The assimilable nitrogen source used was $300 \mathrm{mg} \mathrm{N} / \mathrm{L}$ $(120 \mathrm{mg} \mathrm{N} / \mathrm{L}$ as ammonium and $180 \mathrm{mg} \mathrm{N} / \mathrm{L}$ in an amino acid form).

The competition experiments and experimental evolution were based on batch serial dilution. Batch cultures were prepared in laboratory-scale fermenters using 100$\mathrm{mL}$ bottles filled with $60 \mathrm{~mL}$ of SM1 fitted with closures that enabled carbon dioxide to escape and samples to be removed. The population inoculated in each flask was at an OD of approximately 0.2. Batch selection was performed at $12{ }^{\circ} \mathrm{C}$, with continuous orbital shaking at $100 \mathrm{rpm}$ for 200 generations.

Cultures were allowed to grow through a normal growth curve, with a weekly transfer of a small volume (the volume required to inoculate at an OD of 0.2) of the expanded culture into $60 \mathrm{~mL}$ of fresh medium. Batch cultures were plated on solid YPD at the initial point (0) and at 10, 50, 100, 150, and 200 generations, and 50 colonies of each sampling point were randomly selected and kept at $-80{ }^{\circ} \mathrm{C}$ in $35 \%(\mathrm{v} / \mathrm{v})$ glycerol for further genotyping analyses.

Culture growth was monitored by measuring absorbance at $600 \mathrm{~nm}$ every $48 \mathrm{~h}$. The number of generations was calculated by the equation: $n=\left(\log N_{t}-\log N_{0}\right) / \log$ 2 , where $\mathrm{n}$ is the number of generations, $\mathrm{N}_{0}$ is the initial $\mathrm{OD}$ and $\mathrm{N}_{\mathrm{t}}$ is the $\mathrm{OD}$ at time $\mathrm{t}$. Thus, the generation time $(\mathrm{GT})$ was calculated by the equation $\mathrm{GT}=\mathrm{t} / \mathrm{n}$.

\section{Interdelta sequences typing}

Yeast typing was performed by delta element amplification from genomic DNA. PCR amplifications were carried out in a $50-\mu \mathrm{L}$ reaction containing $5 \mu \mathrm{L}(0.1$ $100 \mathrm{ng}$ ) of DNA, $1 \mu \mathrm{L}$ of $200 \mu \mathrm{M}$ dNTPs, $1 \mu \mathrm{L}$ of $10 \mu \mathrm{M}$ primers, $5 \mu \mathrm{L}$ of $10 \times$ PCR buffer, $2.5 \mu \mathrm{L}$ of $50 \mathrm{mM}$ $\mathrm{MgCl}_{2}, 1 \mu \mathrm{L}$ of BSA $200 \mu \mathrm{g} / \mathrm{mL}, 0.2 \mu \mathrm{L}$ of Taq polymerase and $33.3 \mu \mathrm{L}$ of water to a total volume of $50 \mu \mathrm{L}$. The delta sequence amplification conditions were those described by Legras and Karst [44]. Amplification products were separated by electrophoresis on $1.5 \%(\mathrm{w} / \mathrm{v})$ agarose gels.

\section{Strain construction}

A site-directed mutant was constructed in point mutation $G A A 1^{\text {Thr108 }}$. The URA3 gene was replaced in strain P5 with the KanMX4 gene following the SFH method [46]. After obtaining P5 (ura3::KanMX4), a derivative haploid of this strain was constructed by replacing the $H O$ gene with the HphMX4 (hygromycin resistance) cassette amplified from plasmid pAG32 [47]. Transformants were sporulated to select spores resistant to geneticin and hygromycin. The haploid state of the segregants was confirmed by PCR determination of the MAT locus [48]. After screening growth capacity at the low and optimum temperatures of the $H O$ mutants, the haploid strain most like the parental wine strain was selected. This strain was then used to construct the site-directed mutant by cloning into the centromeric plasmid pGREG526, which contained URA3 as a marker [49]. The GAA1 gene was amplified from approximately 600 nucleotides upstream of the start codon and 400 nucleotides downstream of the stop codon to ensure that the promoter and terminator regions were included. The P5-EM (evolved) strain was used as a template to amplify the $G A A 1^{\text {Thr108 }}$ allele. The plasmid was linearized by SalI digestion and digested with NotI to avoid sticky ends and to make the recombination process easier. The selected haploid P5 (ura3A) strain was co-transformed with the digested pGREG526 plasmid together with the PCR-amplified GAA1 Thr108 allele. This recombination between both fragments occurred in vivo and, during 
this process, the GAL1 promoter of the plasmid was deleted. Thus the GAA1 ${ }^{\text {Thr108 }}$ allele was cloned with its own promoter. As control or reference strain, the haploid P5 (ura3A) strain was also co-transformed with the pGREG526 plasmid together with the wild-type GAA1 allele. Escherichia coli strain DH5 $\alpha$ was used for plasmid amplification. To check the selected clones, genes were sequenced and the presence of the site-directed mutation was confirmed.

\section{Fermentations}

The fermentation experiments with the evolved strains were carried out in the same medium selected for competition experiments and experimental evolution (SM1) and in a more defined synthetic grape must medium (SM2), in which the YNB base was replaced with a defined concentration of mineral salts, as described by Riou et al. [50]; $\mathrm{KH}_{2} \mathrm{PO}_{4} 750 \mathrm{mg} / \mathrm{L}, \mathrm{K}_{2} \mathrm{SO}_{4} 500 \mathrm{mg} / \mathrm{L}$, $\mathrm{MgSO}_{4} 250 \mathrm{mg} / \mathrm{L}, \mathrm{CaCl}_{2} 155 \mathrm{mg} / \mathrm{L}, \mathrm{NaCl} 200 \mathrm{mg} / \mathrm{L}$, $\mathrm{MnSO}_{4} 4 \mathrm{mg} / \mathrm{L}, \mathrm{ZnSO}_{4} 4 \mathrm{mg} / \mathrm{L}, \mathrm{CuSO}_{4} 1 \mathrm{mg} / \mathrm{L}$, KI $1 \mathrm{mg} / \mathrm{L}, \quad \mathrm{CoCl}_{2} \quad 0.4 \mathrm{mg} / \mathrm{L}, \mathrm{H}_{3} \mathrm{BO}_{3} 1 \mathrm{mg} / \mathrm{L}$ and $(\mathrm{NH} 4)_{6} \mathrm{Mo}_{7} \mathrm{O}_{24} 1 \mathrm{mg} / \mathrm{L}$; and vitamins myo-inositol $20 \mathrm{mg} / \mathrm{L}$, calcium pantothenate $1.5 \mathrm{mg} / \mathrm{L}$, nicotinic acid $2 \mathrm{mg} / \mathrm{L}$, chlorohydrate thiamine $0.25 \mathrm{mg} / \mathrm{L}$, chlorohydrate pyridoxine $0.25 \mathrm{mg} / \mathrm{L}$ and biotin $0.003 \mathrm{mg} / \mathrm{L}$. The assimilable nitrogen source used was $300 \mathrm{mg} \mathrm{N} / \mathrm{L}$ $(120 \mathrm{mg} \mathrm{N} / \mathrm{L}$ as ammonium and $180 \mathrm{mg} \mathrm{N} / \mathrm{L}$ in the amino acid form).

Natural grape must (NM) of two grape varieties (Albariño and Macabeo) and one red grape variety (Garnacha) were also fermented by wild strain P5 and their derivative evolved strains (P5-E and P5-EM). The three NMs contained approximately $200 \mathrm{~g} / \mathrm{L}$ of reducing sugars $(100 \mathrm{~g} / \mathrm{L}$ glucose $+100 \mathrm{~g} / \mathrm{L}$ fructose). Prior to inoculation, the natural grape must was treated with $1 \mathrm{ml} / \mathrm{L}$ of Velcorin (trade name for dimethyldicarbonate; Merck, Hohenbrunn, Germany). The use of this antimicrobial agent resulted in the practical elimination of the natural must microbiota, tested by plating on YPD and incubating for $72 \mathrm{~h}$ at $30{ }^{\circ} \mathrm{C}$.

Fermentations were performed in laboratory-scale fermenters using 100-mL bottles filled with $60 \mathrm{~mL}$ of grape must and fitted with closures that enabled carbon dioxide to escape and samples to be removed. Fermentations were run at $28{ }^{\circ} \mathrm{C}$ and $12{ }^{\circ} \mathrm{C}$ with continuous orbital shaking at $100 \mathrm{rpm}$. The population inoculated in each flask was $2 \times 10^{6}$ cells $/ \mathrm{mL}$ from an overnight culture in YPD. Fermentations were monitored by measuring the density of the media $(\mathrm{g} / \mathrm{L})$ using a Densito $30 \mathrm{PX}$ densitometer (Mettler Toledo, Switzerland). Fermentation was considered complete when density was below $998 \mathrm{~g} / \mathrm{L}$. Cell growth was determined by absorbance at $600 \mathrm{~nm}\left(\mathrm{OD}_{600}\right)$.
The fermentation kinetics was calculated by directly fitting density measurements versus time to the fourparameter logistic equation proposed by Speers et al. [51]. The estimation was done using the Sigmaplot software (Systa Software Inc. USA). When data were fitted to the four-parameter logistic equation, an estimation of time for each density value was also obtained. These values were used to calculate T5, T50 and T100. Fermentations were repeated at least 3 times, and data are reported as the mean value \pm SD. Significant differences between strains were determined by $t$-tests (SPSS 13 software package, USA). The statistical level of significance was set at $P \leq 0.05$.

\section{Determination of limiting nutrient during fermentation at low temperature}

The main differences between synthetic grape musts SM1 and SM2 lay in vitamins, anaerobic factors and mineral salt concentration (Additional file 5: Table S2). To determine the limiting nutrient for growing in SM1 at $12{ }^{\circ} \mathrm{C}$, each compound with a different concentration was added individually to SM1 at the same concentration as in SM2, whereas the rest of the compounds remained at the same concentration. Fermentations were carried out as described above.

To determine the limiting concentration of inositol, concentrations ranging from SM1 (2 $\mathrm{mg} / \mathrm{L})$ to SM2 $(20 \mathrm{mg} / \mathrm{L})$ were analyzed by adding aliquots to reach a final concentration of 2, 4, 8, 10,13,13, 17 and $20 \mathrm{mg} / \mathrm{L}$. Fermentation was performed as described before. An ordinary least-square (OLS) regression was used to statistically test the relation between inositol concentration and $\mathrm{OD}_{600} \max$.

\section{Validation of the fitness advantage of evolved strain P5-EM}

A GFP-labeled P5 strain (GFP- KanMX4) [52] was coinoculated with evolved strain P5-EM in SM1 medium to compete during fermentation. The inoculated population was $2 \times 10^{6}$ cells $/ \mathrm{mL}\left(1 \times 10^{6}\right.$ cells $/ \mathrm{mL}$ of each strain). The percentage of each strain throughout fermentation was monitored by both replica plating from YPD to YPD-geneticin (G-418, Formedium) and by flow cytometry. The percentage of fluorescent cells was determined in a flow cytometer (Beckman Coulter Epics XL Flow Cytometer, Minnesota, USA) after GFP induction in YP-Gal (1\% yeast extract, $2 \%$ peptone and $2 \%$ galactose) for $4 \mathrm{~h}$ at $25{ }^{\circ} \mathrm{C}$ (no changes in population size were detected during this incubation). In all, 20000 cells of the sample were measured at a voltage of $700 \mathrm{~V}$ in FL1 FITC, which revealed the number and percentage of fluorescent cells and fluorescence intensity. The EXPO 32 ADC software was used for these measurements. The parameters measured with the cytometer were number 
of fluorescent cells and average fluorescence intensity [53]. In order to rule out that the expression of GFP affects the fitness advantage of the parental P5 strain, a mixed inoculum of both strains (50 \% P5-50 \% P5-GFP) was inoculated in the same conditions explained above. The percentage of both strains was maintained at around $50 \%$ throughout the fermentations, demonstrating that the fitness of the reporter strain did not diminish in comparison to that of the parental strain.

\section{Transcriptome analysis}

Yeast cells $\left(10^{8}\right.$ cells $\left./ \mathrm{mL}\right)$ were collected in the exponential growth phase during fermentation at $12{ }^{\circ} \mathrm{C}$ from three independently cultured replicates. RNA was isolated as described by Sierkstra et al. [54] and was re-suspended in $50 \mu \mathrm{L}$ of DEPC-treated water. Total RNA suspensions were purified by the High Pure Isolation kit (Roche Applied Science, Germany) according to the manufacturer's instructions. Solutions and equipment were treated so that they were RNase-free, as outlined in Sambrook et al. [55].

Microarray services were provided by the IRB Functional Genomics Core Facility, including quality control tests of total RNA by Agilent Bioanalyzer and Nanodrop spectrophotometry. RNA expression profiling was performed following the Pico Profiling method [56]. Briefly, cDNA library preparation and amplification were carried out from 25 ng total RNA using WTA2 (Sigma-Aldrich) with 17 amplification cycles. Eight $\mu$ g of cDNA were subsequently fragmented by DNaseI and biotinylated by terminal transferase obtained from the GeneChip Mapping 250 K Nsp Assay Kit (Affymetrix). The hybridization mixture was prepared according to the Affymetrix protocol. Each sample was hybridized to a GeneChip Yeast Genome 2.0 Array (Affymetrix). Arrays were washed and stained in a Fluidics Station 450 and scanned in a GeneChip Scanner 3000 (both Affymetrix) according to the manufacturer's recommendations. CEL files were generated from DAT files using the GCOS software (Affymetrix). To generate the $\log _{2}$ expression estimates, overall array intensity was normalized between arrays and the probe intensity of all probes in a probe set was summarized to a single value with the RMA (Robust Multichip Average) algorithm [57] in Genomics Suite 6.6 (Partek). $\log _{2}$ ratios were used to calculate the differential expression between strains. The genes with at least 2-fold differences in the transcript levels $\left(\log _{2}\right.$ ratio was $\leq-1$ or $\geq 1$ ) between strains were tested. Genes were considered to have a significant differential expression if the p-values of the Student's $t$-test were $\leq 0.05$ after applying the Benjamini and Hochberg (BH) method to adjust for the false discovery rate (FDR) [58]. To group genes into functional categories, the GO term Finder in the MIPS Functional Catalog was used (http://mips.helmholtz-muenchen.de/funcatDB/).

\section{Illumina sequencing library prep}

Illumina sequencing libraries were constructed from P5 and P5-EM. Genomic DNA was extracted with the Hoffman-Winston DNA preparation method. Bar-coded DNA fragment libraries were prepared by a Nextera DNA sample preparation kit (Epicentre Biotechnologies, Madison, WI) following standard procedures and published recommendations [59].

Briefly, $50 \mathrm{ng}$ of yeast genomic DNA from each strain were tagmented (tagged and fragmented) by the Nextera transposome. The tagmented DNA was purified following the AMPure (Agencourt) purification protocol. Purified tagmented DNA libraries were PCR-amplified with the Nextera PCR Master Mix. PCR-amplified libraries were cleaned following the AMPure (Agencourt) purification procedures, and submitted for sequencing.

\section{Genome mapping and variant calling}

First 591,334 paired-end, $100 \mathrm{bp}$, quality-filtered reads were collected from P5, and 1,793,478 from P5-EM, with the Illumina Hiseq 2000 platform. These strains were sequenced a second time and gave a final yield of 2,138,346 paired-end reads from P5 and 6,459,516 from P5-EM. Reads were aligned to the sacCer3 reference sequence using BWA [60] and default parameters for paired-end reads. Mapped reads were converted into a SAM file format for each strain. A file containing uniquely mapped reads was generated from the original SAM file to obtain a final percent coverage of $89.5 \%$ and $93 \%$ for P5 and P5-EM, respectively. A final filtered mpileup file was generated per strain using samtools [61] with a -C50 filter, as recommended by BWA.

For SNP calling, a filtered VCF file was generated using vcftools, generated from the filtered mpileup file after removing duplicate reads. The filtered VCF file contained 4,278 variant predictions from P5 and 8,212 from P5-EM. Additional filtering using in-house python scripts separated the variants that were identified only in the evolved strain, removed variants that were called in both the evolved and ancestral strain, and annotated the final variant call list [62]. Finally, 96 variants from P5EM were manually examined in Integrative Genome Viewer [63] (IGV) for further prioritization. Variant predictions were validated by Sanger sequencing.

\section{Determination of mannoprotein content}

The total mannoproteins released during fermentation was quantified at the end of the fermentative process. The relative mannoprotein content of the yeast cell wall was also determined. Yeast cells were collected in the exponential growth phase during fermentation at $28{ }^{\circ} \mathrm{C}$ and $12{ }^{\circ} \mathrm{C}, 24 \mathrm{~h}$ and $96 \mathrm{~h}$ respectively, from three independently cultured replicates. 
The mannoprotein quantification method described by Quirós et al. [64] was used. Three $\mathrm{mL}$ of supernatant were gel-filtered through $30 \times 10 \mathrm{~mm}$ Econo-Pac ${ }^{\circ} 10$ DG disposable chromatography columns (Bio-Rad Laboratories, Hercules, CA). Cell and supernatant samples were subjected to acid hydrolysis and filtered through 0.22$\mu \mathrm{m}$ pore size nylon filters (Micron Analitica, Spain). Then samples were analyzed by HPLC for the quantification of the glucose and mannose released during hydrolysis. Significant differences between the mannoprotein content of strain P5 and the evolved strain were determined by t-tests (SPSS 13 software package).

\section{Lipid composition analysis}

Yeast cells (5-10 mg dry mass) were collected in the exponential growth phase during fermentation at $28{ }^{\circ} \mathrm{C}$ and $12{ }^{\circ} \mathrm{C}, 24 \mathrm{~h}$ and $96 \mathrm{~h}$ respectively. Prior to lipid extraction, a $100-\mu \mathrm{L}$ solution of cold methanol and $20 \mu \mathrm{L}$ of EDTA $0.1 \mathrm{mM}$ were added to the yeast cells with $1 \mathrm{~g}$ glass beads ( $0.5 \mathrm{~mm}$, Biospec Products, USA) in Eppendorf tubes, then mixed for $5 \mathrm{~min}$ in a mini-bead-beater8 (Biospec Products, Qiagen, USA). Lipid extraction was performed according to the protocol described by Redón et al. [65]. A lipid analysis was done at the Kansas Lipidomics Research Center (KLRC). An automated electrospray ionization-tandem mass spectrometry (ESI-MS/ MS) approach was used to analyze the lipid composition in these samples, and data acquisition and analyses were carried out as described previously in Friederichs et al. [66]. Precise amounts of internal standards, obtained and quantified as previously described by Welti et al. [67], were added in the following quantities: $0.3 \mathrm{nmol}$ di12:0-PC, $0.3 \mathrm{nmol}$ di24:1-PC, $0.3 \mathrm{nmol}$ 13:0-lysoPC, $0.3 \mathrm{nmol}$ 19:0-lysoPC, $0.3 \mathrm{nmol}$ di12:0-PE, $0.3 \mathrm{nmol}$ di23:0-PE, $0.3 \mathrm{nmol}$ 14:0-lysoPE, $0.3 \mathrm{nmol}$ 18:0-lysoPE, 0.3 nmol di14:0-PG, 0.3 nmol di20:0(phytanoyl)-PG, 0.3 nmol di14:0-PA, $0.3 \mathrm{nmol}$ di20:0(phytanoyl)-PA, 0.2 nmol di14:0-PS, $0.2 \mathrm{nmol}$ di20:0(phytanoyl)-PS, $0.46 \mathrm{nmol}$ 16:0-18:0-PI, $0.33 \mathrm{nmol}$ di18:0-PI, $3.1 \mathrm{nmol}$ tri17:1 TAG, and 4.6 nmol di15:0 DAG. The sample and internal standard mixture were combined with solvents so that the chloroform/methanol/300 $\mathrm{mM}$ ammonium acetate ratio in water was $300 / 665 / 35$, and the final volume was $1.4 \mathrm{~mL}$.

Unfractionated lipid extracts were introduced by continuous infusion into the ESI source on a triple quadrupole MS (4000QTrap, Applied Biosystems). Samples were introduced using an autosampler (LC Mini PAL, CTC Analytics AG, Zwingen, Switzerland), fitted with the required injection loop for the acquisition time and presented to the ESI needle at $30 \mu \mathrm{L} / \mathrm{min}$. The peaks corresponding to the target lipids were identified and molar amounts were calculated in comparison to the two internal standards in the same lipid class.
Phospholipid species were annotated as "Abbreviation of the lipid class" (number of $\mathrm{C}$ in the fatty acyl chains : number of double bounds in the fatty acyl chains). For example, PC (32:2) means Phosphatidylcholine with a total of $32 \mathrm{C}$ and two double bounds in the fatty acids. A principal component analysis (PCA) was done with the lipid composition data.

\section{Availability of supporting data}

The data set supporting the results of this article is available in the Gene Expression Omnibus (GEO) Database repository GSE67428 (http://www.ncbi.nlm.nih.gov/geo/ query/acc.cgi?acc=GSE67428) and in the Sequence Read Archive (SRA) database repository PRJNA277378 (http://www.ncbi.nlm.nih.gov/bioproject/277378). The data set supporting the results of this article is included in the article (and its additional files).

\section{Additional files}

\begin{abstract}
Additional file 1: Figure S1. Strain's dynamics during competition and experimental evolution experiments. Percentages of $S$. cerevisiae wine strains in batch selection cultures in generations 10, 50, 100, 150 and 200 with no mutagenesis treatment (A) and with EMS mutagenesis treatment (B).

Additional file 2: Figure S2. Fermentation kinetics of original and evolved P5 and P17 strains. Fermentation kinetics (measured as density reduction; dashed lines) and growth (measured as $\mathrm{OD}_{600}$; solid lines) of evolved and parental strains: $\mathrm{P} 5$ strains at $12^{\circ} \mathrm{C}$ (A.1) and $28^{\circ} \mathrm{C}$ (B.1) and P17 strains at $12^{\circ} \mathrm{C}$ (A.2) and $28^{\circ} \mathrm{C}$ (B.2). Original strains are represented as filled circles; the strains from the nonEMS treated cultures are represented as open circles; the strains from the EMS-treated cultures are represented as filled triangles.
\end{abstract}

Additional file 3: Figure S3. Fermentation kinetics of P5 and P5-EM in $\mathrm{SM} 2$ and $\mathrm{SM} 1+\mathrm{I}$. Fermentation kinetics (measured as density reduction; dashed lines) and growth (measured as $\mathrm{OD}_{600}$; solid lines) of P5 (filled circles) and P5-EM (open circles) during the fermentation at $12^{\circ} \mathrm{C}$ in SM2 (A) and SM1 + inositol (20 mg/L) (B).

Additional file 4: Table S1. Main nutritional differences between both synthetic grape musts SM1 and SM2.

Additional file 5: Table S2. A significant different gene expression list, with at least 2-fold differences in the transcript levels (log2-fold were $\leq$ -1 or $\geq 1$ ) between P5 and P5-EM during low-temperature fermentation.

Additional file 6: Table S3. Significant up- and down-regulated GO terms in P5-EM during low-temperature fermentation compared with P5. Numbers of genes are between brackets.

Additional file 7: Table S4. Percentage of phospholipid molecular species expressed as the mean \pm SEM (standard error of the mean) of total cellular concentration of these compounds. Symbol $(-) \leq 0.01 \%$. Significant differences $(P \leq 0.05)$, bold letters, was examined with $t$-test and was compared P5-EM with P5 strain in each condition.

Additional file 8: Figure S4. Dynamics of improvement in fermentation performance at $28^{\circ} \mathrm{C}$. Percentage of improvement in the fermentation kinetics at $28{ }^{\circ} \mathrm{C}(\mathrm{T} 5, \mathrm{~T} 25, \mathrm{~T} 50$ and T75) of P5-EM and P5 GAA $1^{\text {Thr } 108}$ compared to P5, and a derivative haploid of P5, respectively.

Additional file 9: Table S5. Yeast strains used in this study.

\section{Abbreviations}

PL: Phospholipid; LPC: Lysophosphatidylcholine;

LPE: Lysophosphatidylethanolamine; PA: Phosphatidic Acid;

PC: Phosphatidylcholine; PE: Phosphatidylethanolamine;

PG: phosphatidylglycerol; PI: Phosphatidylinositol; PS: Phosphatidylserine. 


\section{Competing interest}

The authors declare that they have no competing interests.

\section{Authors' contributions}

MLM conducted most of the experiments, analyzed the data and wrote the manuscript. EGR also conducted the experiments of strain construction and fermentations. BM determined the limiting nutrient in the synthetic must and performed wine fermentations. MRS performed the analysis of yeast genomic sequences. MJD analysed the data, participated in the design of the study and wrote the manuscript. JMG conceived the study, analysed the data and wrote the manuscript. All the authors have read and approved the final manuscript.

\section{Acknowledgments}

This work has been financially supported by grants AGL2013-47300-C3-3$R$ and PROMETEOII/2014/042 from the Spanish government and the Generalitat Valenciana, respectively, awarded to JMG. MLM and EGR also want to thank the Spanish government for her FPI grants. Analysis of yeast genomic sequences was made possible through the NIH P41 GM103533 grant funding the Yeast Resource Center. MJD is a Rita Allen Scholar and Fellow in the Genetic Networks program at the Canadian Institute for Advanced Research. MS was supported by NSF fellowship DGE-1256082. The authors are particularly grateful to Lallemand Company for providing us a collection of their commercial strains.

\section{Author details}

${ }^{1}$ Departamento de Biotecnología de los alimentos, Instituto de Agroquímica y Tecnología de los Alimentos (CSIC), Avda. Agustín Escardino, 7, E-46980 Paterna, Valencia, Spain. ${ }^{2}$ Department of Genome Sciences, University of Washington, Seattle, WA 98195, USA.

Received: 31 March 2015 Accepted: 7 July 2015

Published online: 22 July 2015

\section{References}

1. Beltran G, Novo M, Leberre V, Sokol S, Labourdette D, Guillamón JM, et al. Integration of transcriptomic and metabolic analyses for understanding the global responses of low-temperature winemaking fermentations. FEMS Yeast Res. 2006;6:1167-83.

2. Torija MJ, Beltran G, Novo M, Poblet M, Guillamón JM, Mas A, et al. Effects of fermentation temperature and Saccharomyces species on the cell fatty acid composition and presence of volatile compounds. Int J Food Microbiol. 2003:85:127-36.

3. Bisson L. Stuck and sluggish fermentation. Am J Enol Vitic. 1999;50:107-19.

4. Llauradó JM, Rozès N, Constanti M, Mas A. Study of some Saccharomyces cerevisiae strains for winemaking after preadaptation at low temperatures. J Agric Food Chem. 2005;53:1003-11.

5. Castellari L, Ferruzzi M, Magrini A, Giudici P. Unbalanced wine fermentation cryotolerant vs non-cryotolerant Saccharamyces strains. Vitis. 1994;33:49-52.

6. Giudici P, Caggia C, Pulvirenti A, Ranieri S. Karyotyping of Saccharomyces strains with different temperature profiles. J Appl Microbiol. 1998;84:811-9.

7. Massoutier C, Alexandre H, Feuillat M, Charpentier C. Isolation and characterization of cryotolerant Saccharomyces strains. Vitis. 1998;37:55-9.

8. Salvadó Z, Arroyo-López FN, Guillamón JM, Salazar G, Querol A, Barrio E. Temperature adaptation markedly determines the growth and evolution within the genus Saccharomyces. Appl Environ Microbiol. 2011;77:2292-302.

9. Dequin S. The potential of genetic engineering for improving brewing, wine-making and baking yeasts. Appl Microbiol Biotechnol. 2001;56:577-88.

10. Donalies UE, Nguyen HT, Stahl U, Nevoigt E. Improvements of Saccharomyces yeast strains used in brewing, wine making and baking. Adv Biochem Eng Biotechnol. 2008;111:67-98.

11. Husnik J, Volschenk H, Bauer J, Colavizza D, Luo Z, van Vuuren HJ. Metabolic engineering of malolactic wine yeast. Metab Eng. 2006;8:315-23.

12. Çakar ZP, Turanli-Yildiz B, Alkim C, Yilmaz U. Evolutionary engineering of Saccharomyces cerevisiae for improved industrially important properties. FEMS Yeast Res. 2012;12:171-82.

13. Sonderegger M, Sauer U. Evolutionary engineering of Saccharomyces cerevisiae for anaerobic growth on xylose. Appl Environ Microbiol. 2003;69:1990-8.
14. Guimarães PMR, François J, Parrou JL, Teixeira JA, Domingues L. Adaptive evolution of a lactose-consuming Saccharomyces cerevisiae recombinant. Appl Environ Microbiol. 2008;74:1748-56.

15. Teunissen A, Dumortier F, Gorwa MF, Bauer J, Tanghe A, Loïez A, et al. Isolation and characterization of a freeze-tolerant diploid derivative of an industrial baker's yeast strain and its use in frozen doughs. Appl Environ Microbiol. 2002;68:4780-7.

16. Cadière A, Ortiz-Julien A, Camarasa C, Dequin S. Evolutionary engineering Saccharomyces cerevisiae wine yeast strains with increased in vivo flux through the pentose phosphate pathway. Metab Eng. 2011;13:263-71.

17. Cadière A, Aguera E, Caillé S, Ortiz-Julien A, Dequin S. Pilot-scale evaluation the enological traits of a novel, aromatic wine yeast strain obtained by adaptive evolution. Food Microbiol. 2012;32:332-7.

18. McBryde C, Gardner JM, de Barros Lopes M, Jiranek V. Generation of novel yeast strains by adaptive evolution. Am J Enol Vitic. 2006;57:423-30.

19. Paquin C, Adams J. Frequency of fixation of adaptive mutations is higher in evolving diploid than haploid yeast populations. Nature. 1983;302:495-500.

20. Çakar ZP, Seker UOS, Tamerler C, Sonderegger M, Sauer U. Evolutionary engineering of multiple-stress resistant Saccharomyces cerevisiae. FEMS Yeast Res. 2005:5:569-78.

21. Araya $\mathrm{CL}$, Payen $\mathrm{C}$, Dunham MJ, Fields $\mathrm{S}$. Whole-genome sequencing of a laboratory-evolved yeast strain. BMC Genomics. 2010;11:88.

22. Dunham MJ, Badrane H, Ferea T, Adams J, Brown PO, Rosenzweig F, et al. Characteristic genome rearrangements in experimental evolution of Saccharomyces cerevisiae. Proc Natl Acad Sci U S A. 2002;99:16144-9.

23. Abramova N, Sertil O, Mehta S, Lowry CV. Reciprocal regulation of anaerobic and aerobic cell wall mannoprotein gene expression in Saccharomyces cerevisiae. J Bacteriol. 2001;183:2881-7.

24. Brown SL, Stockdale VJ, Pettolino F, Pocock KF, de Barros Lopes M, Williams $P J$, et al. Reducing haziness in white wine by overexpression of Saccharomyces cerevisiae genes YOL155C and YDR055W. Appl Microbiol Biotechnol. 2007;73:1363-76.

25. Carman GM, Han GS. Regulation of phospholipid synthesis in the yeast Saccharomyces cerevisiae. Annu Rev Biochem. 2011;80:859-83.

26. López-Malo M, García-Ríos E, Chiva R, Guillamón JM. Functional analysis of lipid metabolism genes in wine yeasts during alcoholic fermentation at low temperature. Microb Cell. 2014;1:365-75.

27. Steensels J, Snoek T, Meersman E, Nicolino MP, Voordeckers K, Verstrepen KJ. Improving industrial yeast strains: exploiting natural and artificial diversity. FEMS Microbiol Rev. 2014;38:947-95.

28. Walker ME, Nguyen TD, Liccioli T, Schmid F, Kalatzis N, Sundstrom JF, et al. Genome-wide identification of the fermentome; genes required for successful and timely completion of fermentation by Saccharomyces cerevisiae. BMC Genomics. 2014;15:552.

29. Wenger JW, Piotrowski J, Nagarajan S, Chiotti K, Sherlock G, Rosenzweig F. Hunger artists: Yeast adapted to carbon limitation show trade-offs under carbon sufficiency. PLoS Genet. 2011;7, e1002202.

30. Russell N. Cold adaptation of microorganisms. Phil Trans R Soc Lond. 1990;326:595-611.

31. Fisher E, Almaguer C, Holic R, Griac P, Patton-Vogt J. Glycerophosphocholine-dependent growth requires Gde1p (YPL110c) and Git1p in Saccharomyces cerevisiae. J Biol Chem. 2005;280:36110-7.

32. Patton-Vogt JL, Henry SA. GIT1, a gene encoding a novel transporter for glycerophosphoinositol in Saccharomyces cerevisiae. Genetics. 1998;149:1707-15.

33. de Kroon Al, Rijken PJ, De Smet CH. Checks and balances in membrane phospholipid class and acyl chain homeostasis, the yeast perspective. Progr Lipid Res. 2013;52:374-94.

34. Kapteyn JC, Van Egmond P, Sievi E, Van Den Ende H, Makarow M, Klis FM. The contribution of the O-glycosylated protein Pir2p/Hsp150 to the construction of the yeast cell wall in wild-type cells and beta 1,6-glucandeficient mutants. Mol Microbiol. 1999;31:1835-44.

35. Leidich SD, Kostova Z, Latek RR, Costello LC, Drapp DA, Gray W, et al. Temperature-sensitive yeast GPI anchoring mutants gpi2 and gpi3 are defective in the synthesis of $\mathrm{N}$-acetylglucosaminyl phosphatidylinositol. Cloning of the GPI2 gene. J Biol Chem. 1995;270:13029-35.

36. Fraering $\mathrm{P}$, Imhof I, Meyer U, Strub JM, van Dorsselaer A, Vionnet $\mathrm{C}$, et al. The GPI transamidase complex of Saccharomyces cerevisiae contains Gaa1p, Gpi8p, and Gpi16p. Mol Biol Cell. 2001;12:3295-306.

37. Abe F. Induction of DAN/TIR yeast cell wall mannoprotein genes in response to high hydrostatic pressure and low temperature. FEBS Lett. 2007;581:4993-8. 
38. Rossignol T, Dulau L, Julien A, Blondin B. Genome-wide monitoring of wine yeast gene expression during alcoholic fermentation. Yeast. 2003;20:1369-85.

39. Chiva R, López-Malo M, Salvadó Z, Mas A, Guillamón JM. Analysis of low temperature-induced genes (LTIG) in wine yeast during alcoholic fermentation. FEMS Yeast Res. 2012;12:831-43.

40. Hibbs MA, Hess DC, Myers CL, Huttenhower C, Li K, Troyanskaya OG. Exploring the functional landscape of gene expression: directed search of large microarray compendia. Bioinformatics. 2007;23:2692-9.

41. Pitkänen JP, Törmä A, Alff S, Huopaniemi L, Mattila P, Renkonen R. Excess mannose limits the growth of phosphomannose isomerase PMI40 deletion strain of Saccharomyces cerevisiae. J Biol Chem. 2004;79:5737-43.

42. Worley J, Luo X, Capaldi AP. Inositol pyrophosphates regulate cell growth and the environmental stress response by activating the HDAC Rpd3L. Cell Rep. 2013;3:1476-82.

43. Legras $J$, Karst F. Optimisation of interdelta analysis for Saccharomyces cerevisiae strain characterisation. FEMS Microbiol Lett. 2003;221:249-55.

44. Winston F. EMS and UV mutagenesis in yeast. Curr Protoc Mol Biol. 2008:82:13.3B.1-5

45. Quirós M, Martínez-Moreno R, Albiol J, Morales P, Vázquez-Lima F, Barreiro-Vázquez A, et al. Metabolic flux analysis during the exponential growth phase of Saccharomyces cerevisiae in wine fermentations. PLoS One. 2013:8, e71909.

46. Güldener U, Heck S, Fiedler T, Beinhauer J, Hegemann JH. A new efficient gene disruption cassette for repeated use in budding yeast. Nucleic Acids Res. 1996;24:2519-24.

47. Goldstein AL, McCusker JH. Three new dominant drug resistence cassettes for gene disruption in Saccharomyces cerevisiae. Yeast. 1999;15:1541-53.

48. Huxley C, Green ED, Dunham I. Rapid assessment of S. cerevisiae mating type by PCR. Trends Genet. 1990;6:236.

49. Jansen G, Wu C, Schade B, Thomas DY, Whiteway M. Drag and Drop cloning in yeast. Gene. 2005;344:43-51.

50. Riou C, Nicaud J, Barre P, Gaillardin C. Stationary-phase gene expression in Saccharomyces cerevisiae during wine fermentation. Yeast. 1997;13:903-15.

51. Speers RA, Rogers $P$, Smith B. Non-linear modelling of industrial brewing fermentations. J Inst Brew. 2003;109:229-35.

52. García-Ríos E, López-Malo M, Guillamón JM. Global phenotypic and genomic comparison of two Saccharomyces cerevisiae wine strains reveals a novel role of the sulfur assimilation pathway in adaptation at low temperature fermentations. BMC Genomics. 2014;15:1059.

53. Gutiérrez A, Chiva R, Sancho M, Beltran G, Arroyo-López FN, Guillamón JM. Nitrogen requirements of commercial wine yeast strains during fermentation of a synthetic grape must. Food Microbiol. 2012;31:25-32.

54. Sierkstra LN, Verbakel JM, Verrips CT. Analysis of transcription and translation of glycolytic enzymes in glucose-limited continuous cultures of Saccharomyces cerevisiae. J Gen Microbiol. 1992;138:2559-66.

55. Sambrook J, Fritsch EF, Maniatis T. Methods in yeast genetics: a laboratory manual. Cold Spring Harbor, NY. NY: Cold Spring Harbor Laboratory Press; 1989.

56. Gonzalez-Roca E, Garcia-Albéniz X, Rodriguez-Mulero S, Gomis RR, Kornacker $\mathrm{K}$, Auer $\mathrm{H}$. Accurate expresión profiling of very small cell populations. PLoS One. 2010;5, e14418.

57. Irizarry RA, Bolstad BM, Collin F, Cope LM, Hobbs B, Speed TP. Summaries of Affymetrix GeneChip probe level data. Nucleic Acids Res. 2003;31, e15.

58. Benjamini Y, Hochberg Y. Controlling the False Discovery Rate: A practical and powerful approach to multiple testing. J R Stat Soci. 1995;57:289-300.

59. Adey A, Morrison H, Asan X, Xun X, Kitzman J, Turner E, et al. Rapid, lowinput, low-bias construction of shotgun fragment libraries by high-density in vitro transposition. Genome Biol. 2010;14:R119.

60. Li H, Durbin R. Fast and accurate short read alignment with BurrowsWheeler Transform. Bioinformatics. 2009:25:1754-60.

61. Li H, Handsaker B, Wysoker A, Fennell T, Ruan J, Homer N, et al. The Sequence alignment/map (SAM) format and SAMtools. Bioinformatics. 2009;25:2078-9.

62. Pashkova N, Gakhar L, Winistorfer S, Sunshine AB, Rich M, Dunham MJ, et al. The yeast Alix homolog, Bro1, functions as an ubiquitin receptor for protein sorting into multi vesicular endosomes. Dev Cell. 2013;5:520-33.

63. Robinson JT, Thorvaldsdóttir H, Winckler W, Guttman M, Lander ES, Getz G, et al. Integrative Genomics Viewer. Nature Biotechnol. 2011;29:24-6.

64. Quirós M, Morales P, Pérez-Través L, Barcenilla JM, González R. A new methodology to determine cell wall mannoprotein content and release in wine yeasts. Food Chem. 2011;125:760-6.
65. Redón M, Guillamón JM, Mas A, Rozès N. Effect of lipids supplementation upon Saccharomyces cerevisiae lipid composition and fermentation performance at low temperature. Eur Food Res Tech. 2009;228:833-40.

66. Friederichs JM, Ghosh S, Smoyer CJ, McCroskey S, Miller BD, Weaver KJ, et al. The SUN protein Mps3 is required for spindle pole body insertion into the nuclear membrane and nuclear envelope homeostasis. PLoS Genet. 2011;7, e1002365.

67. Welti R, Shah J, Li W, Li M, Chen J, Burke JJ, et al. Plant lipidomics: Discerning biological function by profiling plant complex lipids using mass spectrometry. Front Biosci. 2002;12:2494-506.

\section{Submit your next manuscript to BioMed Central and take full advantage of:}

- Convenient online submission

- Thorough peer review

- No space constraints or color figure charges

- Immediate publication on acceptance

- Inclusion in PubMed, CAS, Scopus and Google Scholar

- Research which is freely available for redistribution

Submit your manuscript at www.biomedcentral.com/submit
C Biomed Central 